\title{
Meteor trail characteristics observed by high time resolution lidar
}

\author{
Y. J. Liu ${ }^{1}$, J. M. C. Plane ${ }^{2}$, B. R. Clemesha ${ }^{1}$, J. H. Wang ${ }^{3}$, and X. W. Cheng ${ }^{4}$ \\ ${ }^{1}$ Instituto Nacional de Pesquisas Espaciais, Avenida dos Astronautas, 1758, 12227-010 São Jose dos Campos, Brazil \\ ${ }^{2}$ School of Chemistry, University of Leeds, Leeds, UK \\ ${ }^{3}$ Center for Space Science and Applied Research, Chinese Academy of Sciences, Beijing, China \\ ${ }^{4}$ Wuhan Institute of Physics and Mathematics, Chinese Academy of Sciences, Wuhan, China
}

Correspondence to: Y. J. Liu (yingjie@laser.inpe.br)

Received: 30 October 2013 - Revised: 29 July 2014 - Accepted: 22 September 2014 - Published: 29 October 2014

\begin{abstract}
We report and analyse the characteristics of 1382 meteor trails based on a sodium data set of $\sim 680 \mathrm{~h}$. The observations were made at Yanqing $\left(115.97^{\circ} \mathrm{E}, 40.47^{\circ} \mathrm{N}\right)$, China by a ground-based $\mathrm{Na}$ fluorescence lidar. The temporal resolution of the raw profiles is $1.5 \mathrm{~s}$ and the altitude resolution is $96 \mathrm{~m}$. We discover some characteristics of meteor trails different from those presented in previous reports. The occurrence heights of the trails follow a double-peak distribution with the peaks at $\sim 83.5 \mathrm{~km}$ and at $\sim 95.5 \mathrm{~km}$, away from the peak height of the regular Na layer. $4.7 \%$ of the trails occur below $80 \mathrm{~km}$, and $3.25 \%$ above $100 \mathrm{~km} .75 \%$ of the trails are observed in only one $1.5 \mathrm{~s}$ profile, suggesting that the dwell time in the laser beam is not greater than $1.5 \mathrm{~s}$. The peak density of the trails as a function of height is similar to that of the background sodium layer. The raw occurrence height distribution is corrected taking account of three factors which affect the relative lifetime of a trail as a function of height: the meteoroid velocity (which controls the ratio of $\mathrm{Na} / \mathrm{Na}^{+}$ablated); diffusional spreading of the trail; and chemical removal of $\mathrm{Na}$. As a result, the bi-modal distribution is more pronounced. Modelling results show that the higher peak corresponds to a meteoroid population with speeds between 20 and $30 \mathrm{~km} \mathrm{~s}^{-1}$, whereas the lower peak should arise from much slower particles in a near-prograde orbit. It is inferred that most meteoroids in this data set have masses of $\sim 1 \mathrm{mg}$, in order for ablation to produce sufficient $\mathrm{Na}$ atoms to be detected by lidar. Finally, the evolution of longer-duration meteor trails is investigated. Signals at each altitude channel consist of density enhancement bursts with the growth process usually faster than the decay process, and there exists a progressive phase shift among these altitude channels.
\end{abstract}

Keywords. Atmospheric composition and structure (middle atmosphere - composition and chemistry)

\section{Introduction}

The daily influx of extraterrestrial matter into the Earth's upper atmosphere has been deduced to be of the order of $100 \mathrm{t}$ a day (Love and Brownlee, 1993). More than $99 \%$ of this mass flux consists of particles with sizes $<1 \mathrm{~mm}$ (Ceplecha et al., 1998; Love and Brownlee, 1993), and which experience, through aerodynamic friction, heating strong enough to ablate entirely and/or vaporize in the upper atmosphere during their high-speed $\left(11-72 \mathrm{~km} \mathrm{~s}^{-1}\right)$ entry into the atmosphere, resulting in the deposition of metal atoms in the lower thermosphere/upper mesosphere (MLT), forming the permanent layer of metal atoms in this altitude region. Such deposition has also been linked to the formation of sporadic metal layers (Gerding et al., 1999; Grime et al., 1999; Höffner et al., 1999). Although this picture is reasonable, we have to acknowledge that it is not entirely satisfactory as a definitive description of the sequence of processes leading to the formation of the regular metal layers. Such a quantitative description needs precise information on the total amount of matter entering the atmosphere, the spatial and temporal variation of this flux, the properties of the incoming meteoroid population (mass, density, velocity, and chemical composition, etc.), and also a detailed understanding of the ablation process and the recondensation and recombination processes for the released atoms (Gerding et al., 1999).

Ablating meteoroids produce spatially well-defined trails of meteoroid debris in the atmosphere, called meteor trails, which last from seconds to tens of minutes before they are 
dissipated into the ambient atmosphere by chemical and/or diffusive processes. The characteristics of these trails depend on the properties of the meteoroids and their interaction with the atmosphere. This being the case, the study of the trails can provide additional insight into the meteoroid properties, the ablation process, and the dynamics and chemistry of the region. Ground-based resonance lidars have demonstrated the capability of measuring quantitatively these meteor trails (Chu et al., 2000; Gerding et al., 1999; Grime et al., 1999; Höffner et al., 1999; Kane and Gardner, 1993; Liu and Yi, 2004; von Zahn et al., 1999; Zeng and Yi, 2011) as well as the regular metal layers, thus providing a powerful tool to study directly the source of the metal layers in the MLT region. Kane and Gardner (1993), reporting the vertical distribution of 106 meteor trails for the first time, provided important information about the source distribution of the metallic layers, but their system was primarily configured with an integration time of $30 \mathrm{~s}$. This allowed them to see trails which either deposited a tremendous amount of metal atoms or remained in the beam for a relatively long period of time, but shorter duration trails were lost amidst the accumulating return from the background metal layer. Later on, meteor trail detection was carried out on a pulse-by-pulse basis (Gerding et al., 1999; Höffner et al., 1999). Showing that the capability of this type of detection was greatly improved, 114 meteor trails were recorded in $6 \mathrm{~h}$ of operation during the 1996 Leonids meteor shower (Grime et al., 1999). These observations were all performed during meteor showers, although sporadic micrometeoroids, those that do not belong to known showers, make up the bulk of the meteoroids striking the Earth (CampbellBrown and Jones, 2006; Ceplecha et al., 1998). It is also well established that this material gives rise to the upper atmospheric metallic and ion layers observed by lidars and radars (Janches et al., 2006). Zeng and Yi (2011) performed a statistical analysis of $155 \mathrm{Fe}$ meteor trails and $136 \mathrm{Na}$ meteor trails with a time resolution of $4 \mathrm{~s}$, and they pointed out that $95 \%$ of these trails were observable in only one $4 \mathrm{~s}$ profile, which suggests that maybe many trails of much shorter duration were not registered by the lidar.

In this paper, we report the characteristics of 1382 meteor trails based on the extensive lidar observations at the temporal resolution of $1.5 \mathrm{~s}$ at Yanqing $\left(115.97^{\circ} \mathrm{E}, 40.47^{\circ} \mathrm{N}\right)$, China. Section 2 gives a detailed description of the meteor trail extraction method adopted. In Sect. 3, the characteristics of meteor trails are studied, including the occurrence height, the duration, and the distribution of the peak density of both the trails and the regular metal layer. The mean $\mathrm{Na}$ influx rate is also estimated. Given the effects of the fraction of $\mathrm{Na}$ atoms ablated, diffusional removal and chemical removal, the height dependence of the trail duration and occurrence frequency are modelled. Finally, the evolution of long-duration trails is investigated.

\section{Data processing methods}

The data utilized here were obtained by the sodium resonant fluorescence lidar at Yanqing $\left(115.97^{\circ} \mathrm{E}, 40.47^{\circ} \mathrm{N}\right)$, China, from August to September 2010 and from May to December 2011. A total of $\sim 680 \mathrm{~h}$ of valid data were obtained. The time resolution was $1.5 \mathrm{~s}$, and the height resolution $96 \mathrm{~m}$. The specifications of the lidar were described in detail by Liu et al. (2013). The laser beam was expanded by 5 times nominally before it was transmitted into the atmosphere. The divergence of the transmitted laser beam turned out to be less than $0.2 \mathrm{mrad}$. In order to extract meteor trails from the large data set, we followed a method similar to Höffner et al. (1999). For each altitude channel, the statistics of count rate is assumed to follow a Poisson distribution. The mean of the Poisson distribution is calculated by averaging 200 consecutive raw profiles (i.e. $5 \mathrm{~min}$ ). At altitudes of the normal sodium layer, a threshold count of $C_{k}$ is defined with a probability that count rates reach $C_{k}$ less than $10^{-8}$. At altitudes with negligible density of the normal sodium layer, $C_{k}$ is taken as 7.5 counts $/ 96 \mathrm{~m}$, corresponding to a count rate of 0.3 counts $/ 96 \mathrm{~m}$ altitude channel and laser pulse. These criteria are very rigorous, judging from our results. Events that occur in altitude channels $\mathrm{I}$ and $\mathrm{I} \pm 1$ between adjacent profiles are assumed to arise from the same meteor trail. The characteristic parameters of the trail are determined from the strongest signal. In this way, a total of 1382 trails were extracted from $\sim 680 \mathrm{~h}$ of valid observations, corresponding to a detection rate of $\sim 2.03$ trails $^{-1}$, which is far higher than the 0.2 trails $^{-1}$ seen by Kane and Gardner (1993) or that seen by Zeng and Yi (2011), 0.4 trails $^{-1}$. We tried changing the threshold probability from $10^{-8}$ to $10^{-6}$, without significant effect on the result, so we attribute our far higher detection rate to the considerably shorter integration time and higher lidar sensitivity.

\section{Characteristics of meteor trails}

\subsection{Occurrence height}

Figure 1 shows the height distribution of the 1382 lidarobserved meteor trails. These trails appeared between the altitudes of 76.7 and $106.1 \mathrm{~km}$, and $64 \%$ of them occurred below $91 \mathrm{~km}$. The most distinguishing feature of the trail occurrence is that it follows a bi-modal distribution, with an upper peak around $95.5 \mathrm{~km}$ and a lower one around $83.5 \mathrm{~km}$. This is considerably different from the observations of Kane and Gardner (1993) and Zeng and Yi (2011), where meteor trail occurrence tended to peak around $90 \mathrm{~km}$. It is interesting to observe that, during an unknown meteor shower, the altitude distribution of 26 lidar-observed $\mathrm{Ca}$ trails also showed a clear double-peaked shape, with the lower peak at $82-83 \mathrm{~km}$ and the higher peak around 94-95 km (Gerding et al., 1999). Although their sample size is quite small, the 


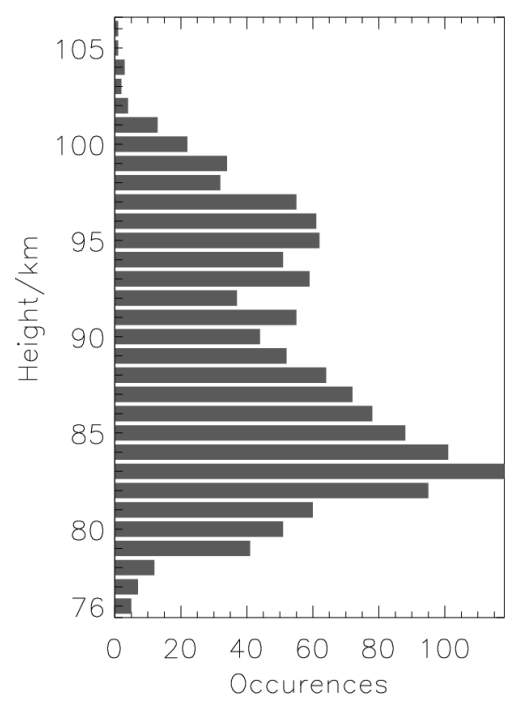

Figure 1. The height distribution of the lidar-observed meteor trails.

similarity between the trail peak height distribution observed by Gerding et al. (1999) and that observed by us appears to be significant. This behaviour may be related to our higher detection capability, able to detect weaker trails far from the peak height, while the other two groups only counted the most dense trails near the background peak height. We believe that this altitude distribution is most likely to reflect the sources (and hence velocities) of incoming meteoroids, because faster-moving meteoroids ablated at higher altitudes (Chu et al., 2000; Kane and Gardner, 1993). Interestingly, the EISCAT radar observing meteor head echoes also showed a double-peak distribution, except that the upper peak occurred around $101.3 \mathrm{~km}$ and the lower one around $94.0 \mathrm{~km}$ (Brosch et al., 2010), well above the lidar-observed meteor trails. Furthermore, the nonspecular meteor trail observed by radar is typically about $10 \mathrm{~km}$ higher than that observed by lidar (Sugar et al., 2010). In the latter study over 2100 trails extended from 86 to $120 \mathrm{~km}$ and $97 \%$ of them occurred between 90 and $110 \mathrm{~km}$. Combining these observations, we can conclude that on the whole the radar-observed ionic meteor trails ablated at higher altitudes than the lidar-observed atomic meteor trails, which is to be expected in view of the fact that the ionization probability of the evaporating constituents depends both on meteoroid velocity and chemical composition (Vondrak et al., 2008).

It should also be noted that quite a lot of atomic trails $(65$ events) were detected below $80 \mathrm{~km}$, accounting for $4.7 \%$, and that 45 meteor trails were observed above $100 \mathrm{~km}$, accounting for $3.25 \%$. Obviously, the relatively low occurrence rate of meteor trail on the topside of the metal layer is not caused by the lidar sensitivity that decreases with increasing altitude. These results are different from those of Kane and Gardner (1993), where no trails were found below $82 \mathrm{~km}$ or above $96 \mathrm{~km}$. This behaviour has been ascribed to

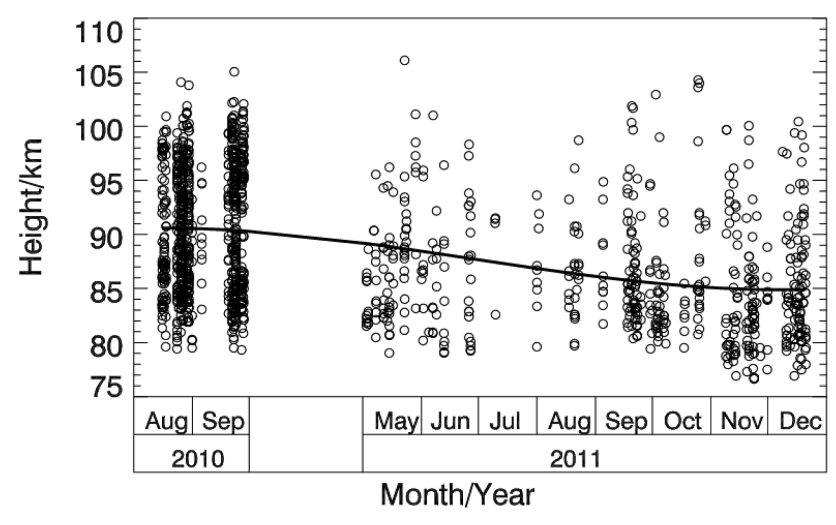

Figure 2. Long-term variation of the occurrence height of the trails.

the dominant chemical removal of metal atoms on the bottom side and rapid diffusion dilution on the upper side of the region (Höffner et al., 1999; Kane and Gardner, 1993; Xu and Smith, 2003). On the other hand it might just be a matter of sample size.

The long-term variation of the trail occurrence height was also investigated, as shown in Fig. 2. Quite a number of trails were observed around $95 \mathrm{~km}$ in August and September 2010, while the data sets in these two months are not larger than those in the other months, so it is not due to measurement statistics. We think it may be associated with the 2010 Perseid meteor shower; another factor may be the increased contribution of meteoroids from the Helion source during summer at mid-latitudes (Pifko et al., 2013). During the other months quite a few trails were observed above $91 \mathrm{~km}$. This bi-modal distribution may reflect a combination of meteoroids from the Helion, anti-Helion, North Toroidal and South Toroidal sources, which have a velocity of around $30 \mathrm{~km} \mathrm{~s}^{-1}$ (Pifko et al., 2013), together with anti-Apex meteoroids in near-prograde orbits with velocities of around $17 \mathrm{~km} \mathrm{~s}^{-1}$ (Pifko et al., 2013).

\subsection{Duration of trails observed in the lidar beam}

The duration of meteor trails reflects the combined effects of meteoroid ablation and altitude-dependent chemical removal, together with molecular and eddy diffusion dilution (Höffner et al., 1999). Owing to the extremely small field of view of the lidar, meteoroids will rarely cross directly the laser beam during their flight through the Earth's upper atmosphere, so it is the trail left behind by the evaporating meteoroids that is seen by the lidar, which is blown by the upper atmosphere winds through the vertically directed laser beam (Gerding et al., 1999; Höffner et al., 1999). Consequently, the apparent duration of meteor trails observed by lidar is the residence time of the trail in the laser beam, generally of the order of seconds. Here we investigate the duration of these 1382 lidar-observed meteor trails. They spanned a wide range of time. The shortest-duration trail was 


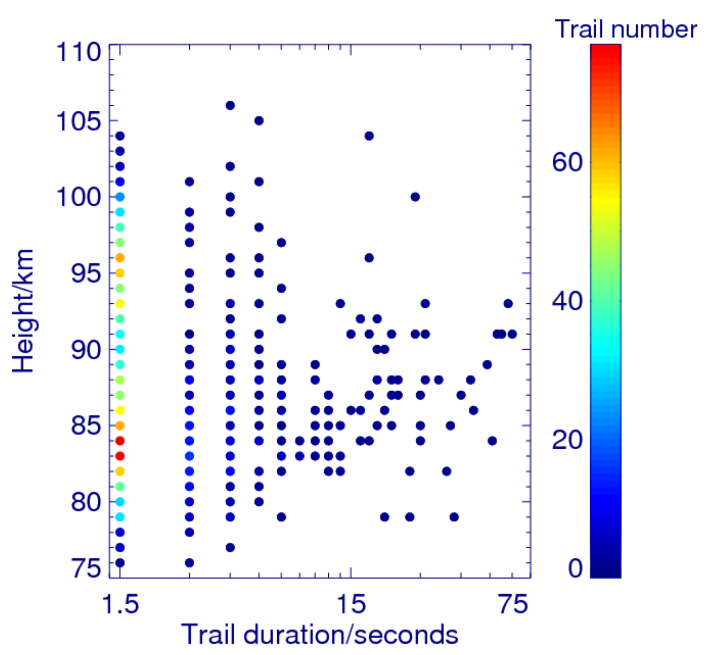

Figure 3. The distribution of the meteor trail duration with the occurrence height.

observed only in one profile - that is, not more than $1.5 \mathrm{~s}$; the longest duration trail was observed in 50 consecutive profiles, $\sim 75 \mathrm{~s}$. Of all trails, $75 \%$ (1039) were observed only in one profile, $\sim 1.5 \mathrm{~s}$. Trails with a duration longer than $1.5 \mathrm{~s}$ were seen only rarely. Those lasting between 3 and $4.5 \mathrm{~s}$ accounted for $9 \%$ of the total, and those lasting between 4.5 and $6 \mathrm{~s}$ accounted for only $6 \%$. Trails with durations between 6 and $7.5 \mathrm{~s}$ only represented $2.5 \%$, and durations between 7.5 and $9 \mathrm{~s}, 1.67 \%$. The total number of trails that lasted longer than $7.5 \mathrm{~s}$ accounted for only $5.5 \%$. We can reasonably assume that these percentages are governed by meteoroid mass/velocity, chemistry and diffusion, together with horizontal wind velocity, as illustrated in Sect. 3.5.

Figure 3 shows the distribution of trail duration with the occurrence height. Although they were dispersed over a wide range, it can be seen that the duration distribution of these trails took on a triangular form as a whole - that is, longerduration trails tended to appear within a certain height range. Meteor trails with duration greater than $7.5 \mathrm{~s}$ occurred at $87.6 \mathrm{~km}$ on average, with a standard deviation of $4.3 \mathrm{~km}$. These values are clearly different from those observed during the 1996 Leonid shower, where two groups of K meteor trails were observed, one group less than $10 \mathrm{~s}$ and the other in the range of 100-2000 s, with the tendency for longer trail durations to be associated with higher altitudes (Höffner et al., 1999). It should be noted that the very long duration trails are quite different in appearance to the shorter-duration trails so we cannot be sure that they are, indeed, meteor trails. In fact, it seems unlikely that a meteor trail could stay within the narrow FOV of the lidar for such a long period of time. During an unknown meteor shower, the duration of $26 \mathrm{Ca}$ meteor trails and $4 \mathrm{~K}$ meteor trails varied from 2 to $281 \mathrm{~s}$ with a median of $9 \mathrm{~s}$ (Gerding et al., 1999), far longer than our median duration of $1.5 \mathrm{~s}$. The great difference among these trail

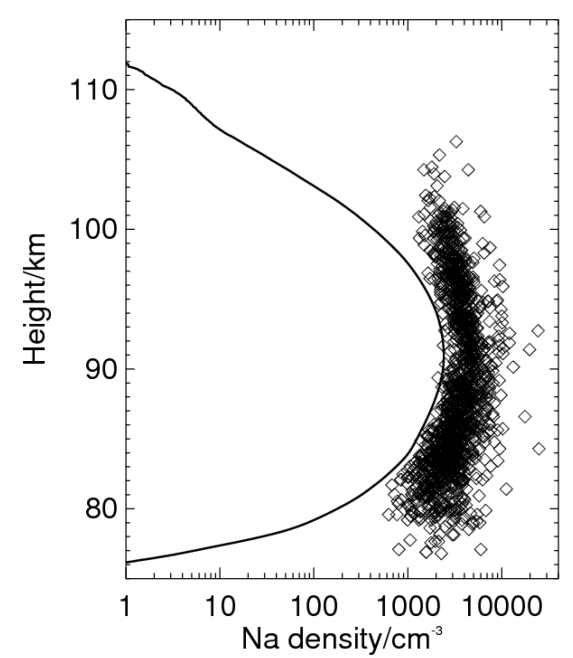

Figure 4. The distribution of the meteor trail peak density with the occurrence height.

durations suggests that most of the meteor trails observed here are associated with sporadic meteoroid populations.

Note that the overwhelming majority $(75 \%)$ of these trails were observed in only one $1.5 \mathrm{~s}$ profile. The shortest observable trail duration, i.e. the shortest transit time in the laser beam, is determined by the diameter of the laser beam and the wind velocity in the region. Considering the divergence angle of the laser beam of less than $0.2 \mathrm{mrad}$, advection of these trails through the laser beam by the wind would certainly be expected to influence their apparent lifetime. Further experiments with different laser beam divergences could help clarify this question.

\subsection{Peak density}

Figure 4 shows the peak density of the 1382 meteor trails plotted as a function of height. The continuous line in this figure shows the average background layer. The peak density of each meteor trail was calculated following a method of Gerding et al. (1999). The minimum peak density of these trails was $625 \mathrm{~cm}^{-3}$ and the maximum was $24815 \mathrm{~cm}^{-3}$. The mean peak density was $3540 \mathrm{~cm}^{-3}$, which is far lower than observed by Kane and Gardner (1993) and Zeng and Yi (2011), which indicates that our lidar is capable of detecting very weak meteor trails. Although the occurrence height of these trails took on a bi-modal distribution as shown in Fig. 1, their peak densities were distributed much like the background $\mathrm{Na}$ layer, which could be associated with the rapid diffusion on the topside and the dominant chemical removal of metal atoms on the bottom side of the layer. That the upper limit at which meteor trails are observed appears to be lower than the upper boundary of the sodium layer, probably is a result of the data processing method used. In order to exclude spikes caused by statistical fluctuations of the count rate, the threshold count $C_{k}$ is taken as 7.5 counts $/ 96 \mathrm{~m}$ at 
altitudes with negligible density of the normal sodium layer, corresponding to a count rate of 0.3 counts $/ 96 \mathrm{~m}$ altitude channel and laser pulse. This is three times that used by Zeng and Yi (2011). Consequently, only signals that are significantly higher than the background are identified as meteor trails, which is also reflected in Fig. 4. The centroid height and the root-mean-square (rms) width of the trail distribution and the corresponding background $\mathrm{Na}$ layer parameters are listed in Table 1. The uncertainties of the centroid height and the rms width of these trails are 0.01 and $0.03 \mathrm{~km}$, respectively. The results of similar observations from the literature are also given here. The centroid heights of these trails observed at the three different stations were $\sim 89.3 \mathrm{~km}$ (Yanqing), $\sim 90.0 \mathrm{~km}$ (Wuhan) and $\sim 89.0 \mathrm{~km}$ (Urbana), respectively, although there was a great difference between the occurrence height distributions, which indicates that the centroid heights of these trails are mainly determined by the strong trails. The separation in altitude between the centroids of the background $\mathrm{Na}$ layer and the meteor trail distributions from Table 1 was about 1.6, 0.7 and $3.1 \mathrm{~km}$, which indicates that the centroid height of the meteor trail distribution approaches that of the background layer. It can be seen from Table 1 that the centroid height of the trails was always observed to be lower than that of the background $\mathrm{Na}$ layer. Unlike the observations reported from other lidars, the rms width of the meteor trail height distribution observed here was larger than that of the background $\mathrm{Na}$ layer, which indicates that these trails deposited throughout the entire $\mathrm{Na}$ layer height range. The bi-modal occurrence height distribution with peaks far from $90 \mathrm{~km}$, as shown in Fig. 1, also suggests that in the short term it is not chemistry that dominates the sodium layer, since meteoric atoms deposited near $90 \mathrm{~km}$ should have a far greater chance of being observed by the lidar because of the longer chemical lifetime expected at this height (Kane and Gardner, 1993; Xu and Smith, 2003).

As shown in Fig. 4, the inner boundary of the trail number density plot follows the shape of the regular Na layer, which could be interpreted as suggesting that the trail density distribution might have resulted from our data processing method, leading us to re-examine our method of calculating the threshold value $C_{k}$. The $5 \mathrm{~min}$ averages of the returned photon counts are adopted as the reference for the threshold $C_{k}$. They usually take on a shape quite different from the long-term background, and sometimes they even exhibit a depression near the background peak, thus we believe that the trail density distribution represents a real geophysical phenomenon rather than an artificial effect.

\subsection{Input fluxes of $\mathrm{Na}$ atoms estimated from meteor trails}

The gas-phase metal input flux is a key parameter for modelling the Na layer. Following the method used by Kane and Gardner (1993) and Zeng and Yi (2011) - the input flux of atomic $\mathrm{Na}$ from lidar meteors is the product of the average trail abundance and the average event rate - we have estimated a mean $\mathrm{Na}$ input flux of $2.2 \times 10^{4} \mathrm{atom}^{-2} \mathrm{~s}^{-1}$, and consequently an influx of meteoric debris into the mesosphere of $\sim 75$ tons per day $\left(\mathrm{td}^{-1}\right)$ was inferred. However, this method needs to be corrected for two factors, and this can only be done rather approximately. First, trails that are observed in the lidar beam are both ablated within the beam (i.e. created nearly instantaneously) and transported by the horizontal wind. Taking an average zonal wind speed of $30 \mathrm{~m} \mathrm{~s}^{-1}$ for Yanqing (CIRA-86), and a trail lifetime of up to $10 \mathrm{~s}$, then the lidar samples trails created in an area of $4800 \mathrm{~m}^{2}$, not just the $201 \mathrm{~m}^{2}$ area of the beam itself. This means that the measured estimate should be reduced by the ratio of these areas to $3 \mathrm{td}^{-1}$. The second problem is that the lidar samples a subset of the total population of meteoroids - smaller particles create trails that are undetectable against the background Na layer. Since the mass contribution of $1 \mathrm{mg}$ or larger meteoroids to the total mass input is about $8 \%$ (Plane, 2012), then the total input would be around $38 \mathrm{td}^{-1}$. Although this estimate is rather approximate, it is considerably larger than the value of $4.6 \mathrm{t} \mathrm{d}^{-1}$ used in a recent global modelling study of the Na layer (Marsh et al., 2013). This may indicate that vertical transport in the middle atmosphere is considerably faster than is generally thought to be the case (Plane, 2012), or that $\mathrm{Na}$ is converted more rapidly into stable reservoir compounds - for instance, meteoric smoke particles.

\subsection{Modelling the height dependence of the trail duration and occurrence frequency}

The raw height distribution of the trail occurrence in Fig. 1 needs to be corrected for three factors which affect the probability of observing a meteor trail before the freshly ablated $\mathrm{Na}$ merges into the background $\mathrm{Na}$ layer. First is the fraction of $\mathrm{Na}$ which ablates from a meteoroid as neutral $\mathrm{Na}$ atoms (which are detected by the lidar), rather than $\mathrm{Na}^{+}$ions. This fraction is governed by the speed of the meteoroid since ionization is caused by hyperthermal collisions of $\mathrm{Na}$ atoms with air molecules. Meteoroids enter the terrestrial atmosphere at speeds ranging from 12 to $71 \mathrm{~km} \mathrm{~s}^{-1}$, and the corresponding fraction of neutral $\mathrm{Na}$ atoms ranges from 98 to $9 \%$ (Vondrak et al., 2008). Faster meteoroids ablate higher in the atmosphere, and thus deposit less neutral sodium than slower meteoroids of similar masses. This relationship between speed, height of ablation, and amount of ablated $\mathrm{Na}$ is illustrated in Fig. 5a for the case of a $1 \mathrm{mg}$ meteoroid with a range of speeds (note that if collisional ionization of $\mathrm{Na}$ did not occur, the integrated areas of each ablation profile would be the same). These ablation profiles are calculated using the CABMOD model at the University of Leeds (Vondrak et al., 2008). It should be noted that this particle mass is within the upper limit of $5 \mathrm{mg}$ where heat transfer is treated correctly because the particle remains isothermal during ablation (Vondrak et al., 2008). 
Table 1. The parameters of meteor trails and background Na layer observed by different groups.

\begin{tabular}{lrrr}
\hline & $\begin{array}{r}\text { Yanqing } \\
\end{array}$ & $\begin{array}{r}\text { Wuhan } \\
\left(40.47^{\circ} \mathrm{N}, 115.97^{\circ} \mathrm{E}\right)\end{array}$ & $\begin{array}{r}\text { Urbana } \\
\left(30.37^{\circ} \mathrm{N}, 114.39^{\circ} \mathrm{E}\right)\end{array}$ \\
$\left(40.11^{\circ} \mathrm{N}, 88.21^{\circ} \mathrm{W}\right)$
\end{tabular}

The second factor to take into account is removal of $\mathrm{Na}$ atoms in a fresh meteor trail due to diffusion. Below about $100 \mathrm{~km}$ this is controlled by turbulence, characterized by an eddy diffusion coefficient, $K_{z z}$; at higher altitudes, molecular diffusion is more important and is described by the diffusion coefficient of $\mathrm{Na}$ in $\mathrm{N}_{2}, D_{\mathrm{Na}}$ (Plane, 2003). The first-order removal rate of $\mathrm{Na}$ by diffusion out of a cylinder with a radius defined by the lidar beam $(r \sim 8 \mathrm{~m}$ at $90 \mathrm{~km})$, is given by the "long-time" solution to the diffusion equation for the case where the length of the cylinder is much greater than the radius (Crank, 1975):

$k_{\text {diff }}=\frac{(2.41)^{2} \max \left(K_{z z}, D_{\mathrm{Na}}\right)}{r^{2}}$.

Figure $5 \mathrm{~b}$ illustrates the diffusional removal rate as a function of height. $K_{z z}$ is taken from the TIME-GCM global model (Wang et al., 1999), and $D_{\mathrm{Na}}$ has been measured in the laboratory (Helmer and Plane, 1993).

The third factor to take into account is chemical removal of $\mathrm{Na}$ (Plane, 2004). The reaction

$\mathrm{Na}+\mathrm{O}_{3} \rightarrow \mathrm{NaO}+\mathrm{O}_{2}$

is rapid below $100 \mathrm{~km}$ (time constant $<10 \mathrm{~s}$ ). However, $\mathrm{NaO}$ is even more rapidly recycled by atomic $\mathrm{O}$ to $\mathrm{Na}$ :

$\mathrm{NaO}+\mathrm{O} \rightarrow \mathrm{Na}+\mathrm{O}_{2}$

Hence, above $82 \mathrm{~km}$ where there is a large concentration of atomic $\mathrm{O}$ during both day and night (Plane, 2003), the chemical (e-folding) lifetime of $\mathrm{Na}$ is comparatively long (>10 s) against removal to a long-lived reservoir such as $\mathrm{NaOH}$ and $\mathrm{NaHCO}_{3}$. The rate of conversion of $\mathrm{Na}$ to $\mathrm{Na}^{+}$ via charge transfer with ambient $\mathrm{NO}^{+}$and $\mathrm{O}_{2}^{+}$ions is very slow $\left(>10^{4} \mathrm{~s}\right)$. Atomic $\mathrm{Na}$ and its compounds can also be removed by uptake onto meteoric smoke particles (Plane, 2004). However, this process is several orders of magnitude slower than the gas-phase chemistry: rocket-borne dust detectors observe about 1000 smoke particles $\mathrm{cm}^{-3}$, between $1-2 \mathrm{~nm}$ in radius (Rapp et al., 2007); taking the larger radius (volumetric surface area $=5 \times 10^{-10} \mathrm{~cm}^{2} \mathrm{~cm}^{-3}$ ) and assuming an uptake coefficient of unity, the e-folding time for uptake is about 2.5 days. The chemical removal rate, illustrated in Fig. 5b, can be calculated using the expression derived by Plane (2003; terms $C$ and $D$ in Eq. 4 on p. 630), with the profiles of background species concentrations and temperature for $40^{\circ} \mathrm{N}$ spring (Plane, 2004). Figure 5b shows that chemical removal exceeds diffusional removal of $\mathrm{Na}$ only below $75 \mathrm{~km}$. Note that there is a minimum in the total removal rate at $82-83 \mathrm{~km}$, and that diffusional removal becomes very fast above $100 \mathrm{~km}$.

The lifetime of a trail can be defined as the maximum time during which a trail could be observed by the lidar. This lifetime can be estimated from the time it would take the $\mathrm{Na}$ in the trail to decay through diffusional and chemical removal to $50 \%$ above the background $\mathrm{Na}$ concentration at the height of the trail. The initial $\mathrm{Na}$ in the trail can be determined by using the ablation profile at the relevant height from Fig. 5a. Figure 5c illustrates this lifetime as a function of height, for $1 \mathrm{mg}$ meteoroids. The maximum lifetime of around $7 \mathrm{~s}$ is at $83 \mathrm{~km}$. Inspection of Fig. 3 shows that most of the trails observed in this study have lifetimes below $10 \mathrm{~s}$, so this choice of meteoroid mass seems appropriate to the bulk of lidar data sets. Furthermore, Fig. 3 shows that the height distribution of long-duration trails with observed durations under $15 \mathrm{~s}$ peaks around $85 \mathrm{~km}$. This agreement of the model with the observations suggests that the choice of $1 \mathrm{mg}$ meteoroids is reasonable.

The probability of observing a trail at a particular height will be proportional to its lifetime. Hence, the height distribution of raw occurrence frequency shown in Fig. 1 can be weighted by the relative lifetime as a function of height. Figure 6 compares the weighted and raw height distributions. The bi-modal distribution is much more pronounced in the weighted distribution, with clear peaks at 83 and $96 \mathrm{~km}$. Comparison with Fig. 5a indicates that the higher peak is produced by a meteoroid population with speeds between 20 and $30 \mathrm{~km} \mathrm{~s}^{-1}$, which probably corresponds to meteoroids from the non-Apex sources (Helion, Anti-Helion, and North and South Toroidal; Pifko et al., 2013), whereas the lower peak should arise from much slower particles in a nearprograde orbit (i.e. the anti-Apex source; Pifko et al., 2013). The weighted distribution in Fig. 6 therefore suggests that the majority of detected meteoroids have speeds between 20 and $30 \mathrm{~km} \mathrm{~s}^{-1}$. However, this needs to be treated with some caution: most of the incoming meteoric mass is contained in particles with masses around $10 \mu \mathrm{g}$ (Plane, 2012), 100 times smaller in mass than the $\sim 1 \mathrm{mg}$ particles which ablate sufficient $\mathrm{Na}$ for the trails to be detectable by lidar. It is possible that the smaller particles have different sources 

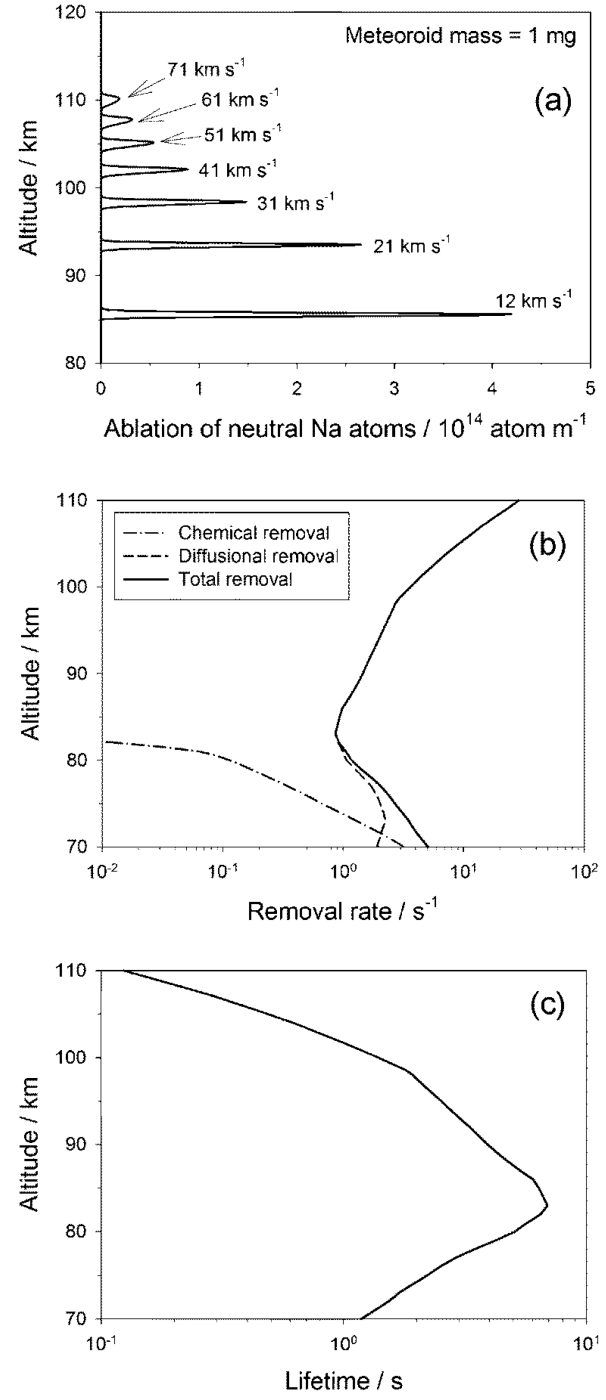

Figure 5. Modelling results: (a) the ablated mass for a $1 \mathrm{mg}$ meteoroid with different entry velocity; (b) variation of the removal rate with altitude due to diffusion and chemistry; (c) the dependence of meteor trail lifetime with altitude.

in the solar system, and so their velocity distribution may be quite different. A final point is that meteoroids from the Apex source (i.e. near-retrograde orbits) have velocities of around $55 \mathrm{~km} \mathrm{~s}^{-1}$ (Pifko et al., 2013) and would therefore produce undetectable trails: firstly, because most of the ablated $\mathrm{Na}$ would be ionized (Fig. 5a), and secondly, because the trails would be well above $100 \mathrm{~km}$ and therefore have very short lifetimes against diffusion (Fig. 5b and c).

\section{The evolution of meteor trails with long durations}

Meteor trail parameters provide information on the ablation process and the chemical and dynamical processes in the region. The characteristic evolution of long-duration trails

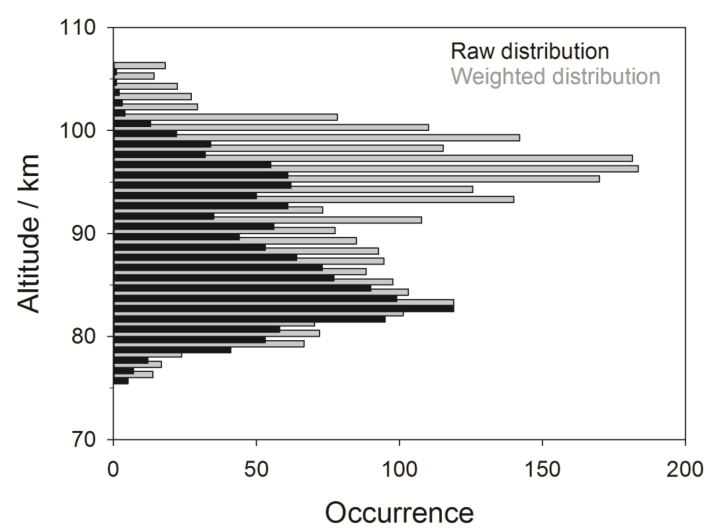

Figure 6. The weighted (grey) and raw (black) height distributions of meteor trails.

should help promote our understanding of these processes. Among the 1382 lidar-observed meteor trails, a total of 76 trails with durations longer than $7.5 \mathrm{~s}$ were identified. Trails were frequently observed to occur at more than one altitude channel even during the same density enhancement burst. This is consistent with the observations of Gerding et al. (1999).

\section{Case 1: meteor trails on the bottom side of the sodium layer}

Figure 7 shows an example on the bottom side of the background sodium layer, which was observed on 24 October 2011. Unlike other meteor trails, it was very strong compared to the background, thus minimizing the influence of the background layer and making it easier to distinguish the evolution of the trail. It was observed in the laser beam for nine consecutive profiles, about $13.5 \mathrm{~s}$. Initially, it was very weak and was hardly detectable. Suddenly, the layer reappeared at $83.352 \mathrm{~km}$, and continued intensifying, reaching a maximum of 4840 atoms $\mathrm{cm}^{-3}$. Next, it began to decay, but the strongest part of the trail by then had risen to a new height, $83.448 \mathrm{~km}$, one altitude channel higher than the original. Meanwhile, the trail started to broaden downward. It then decayed substantially until another peak occurred at a lower altitude of $83.256 \mathrm{~km}$, and the trail at the original height almost disappeared. Subsequently it continued decaying slowly at the lower altitude of $83.256 \mathrm{~km}$ before vanishing completely, but the higher peak had disappeared completely within $1.5 \mathrm{~s}$.

Figure 8 illustrates the detailed variations of the trail intensity, the width and the peak height. It experienced obvious growth and decay processes. It grew to a maximum after $\sim 3 \mathrm{~s}$, and faded away after $\sim 9 \mathrm{~s}$. It was detected in three altitude channels of $96 \mathrm{~m}$ during the whole period. It widened first and then narrowed. As a whole, it ascended by one altitude channel first, and then descended by two altitude channels. Following the method of Liu et al. (2013), the 


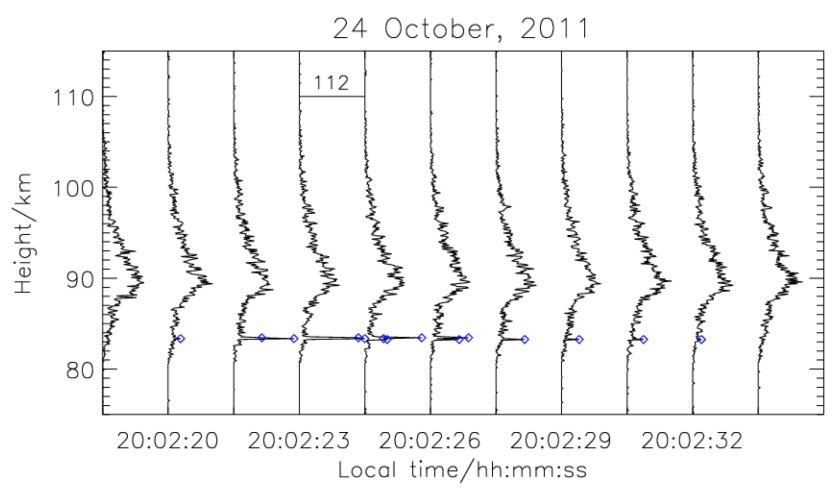

Figure 7. Evolution of a typical meteor trail observed on the bottom side of the Na layer, which occurred on 24 October 2011.

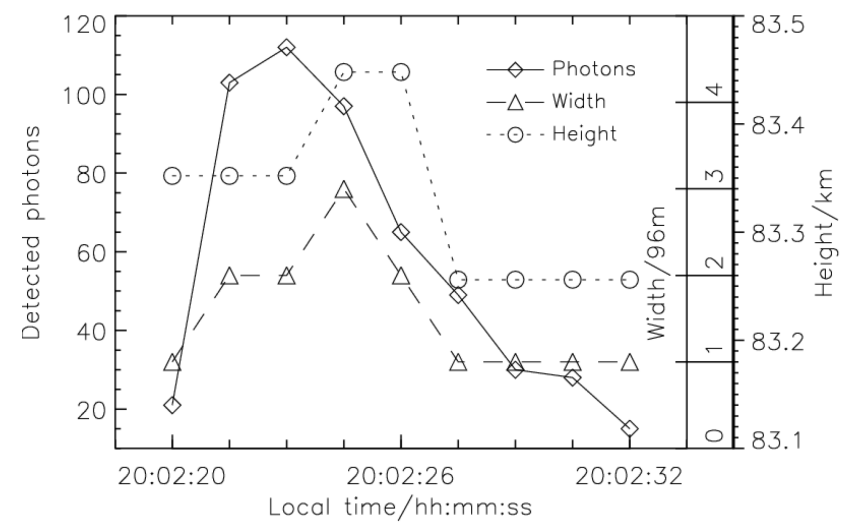

Figure 8. Variations of the trail peak intensity, the width and the peak height, corresponding to Fig. 7.

measurement uncertainty in the peak height was estimated to be only $\sim 50 \mathrm{~m}$ even for a meteor trail with the full width of $600 \mathrm{~m}$ at $1 / e$ times the peak photon count. In fact, most meteor trails have widths less than $600 \mathrm{~m}$. Consequently, the measurement uncertainties in the peak height should be less than $50 \mathrm{~m}$, while the amplitudes of vertical motions usually cover several altitude channels, i.e. several hundreds of metres. So these altitude variations should be real rather than the result of the binning to discrete altitude channels of the lidar.

To investigate the trail evolution, the lidar returns from six neighbouring altitude channels are shown in Fig. 9. Signals from $83.160 \mathrm{~km}$ and from $83.640 \mathrm{~km}$ did not show any obvious variation, which indicates that they were not influenced by the trail event. Signals from the other four altitude channels all exhibited an obvious increase and decrease process during the trail event. Signals from 83.352 and $83.448 \mathrm{~km}$ (i.e. the central parts of the trail) behaved similarly. Signals from 83.256 and $83.544 \mathrm{~km}$ (i.e. the lowermost and the uppermost) also varied similarly. Although the defined uppermost part never reached the preset trail threshold, it can be judged that it was part of the trail. Most importantly, the lowermost part experienced the largest growth just when

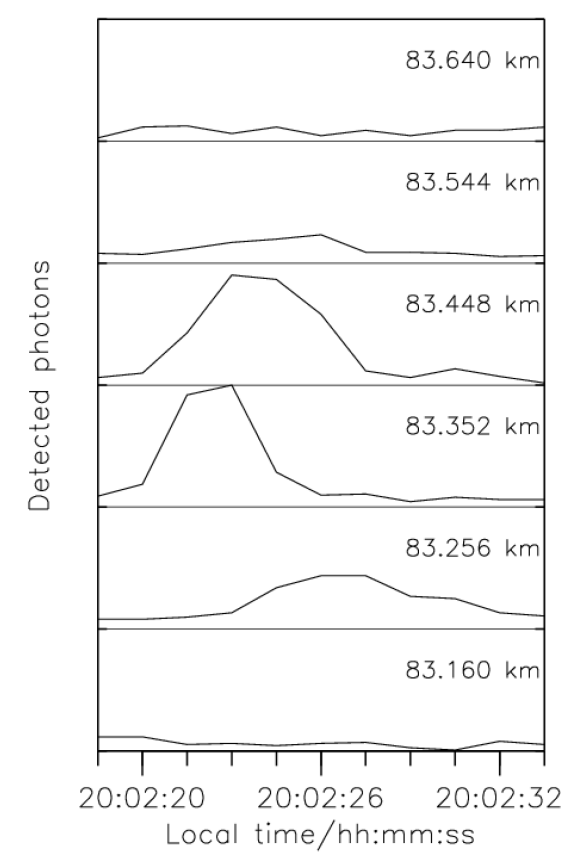

Figure 9. Temporal variation of the lidar returned signals at different altitudes, corresponding to Fig. 7.

the central part decayed by the largest extent, and the trail widened at the same time. Judging from the time shifts of the growth process between the different altitudes, there should be some link among them.

Now we will investigate the decay process of the trail. At 20:02:26 LT, there appeared two strong peaks for the trail. Soon after the upper peak almost disappeared and the lower hardly changed, and $\mathrm{Na}$ concentrations at adjacent heights either decreased or hardly changed. It is very unlikely that differences in the chemical removal rates were responsible for this. As shown in Fig. 5b, the chemical removal rate at $83 \mathrm{~km}$ is quite slow, around $10^{-2} \mathrm{~s}^{-1}$. This arises because there are significant quantities of atomic $\mathrm{O}$ and $\mathrm{H}$ at this altitude, which efficiently recycle back to $\mathrm{Na}$ the compounds such as $\mathrm{NaO}, \mathrm{NaO}_{2}$ and $\mathrm{NaOH}$ that are produced by the oxidation of $\mathrm{Na}$ in the presence of $\mathrm{O}_{3}, \mathrm{O}_{2}$ and $\mathrm{H}_{2} \mathrm{O}$ (Plane, 2004). The stable reservoir species, $\mathrm{NaHCO}_{3}$, is therefore formed relatively slowly by the addition of $\mathrm{CO}_{2}$ to $\mathrm{NaOH}$. $\mathrm{Na}$ atoms at $83.448 \mathrm{~km}$ could therefore only be chemically removed if there were very small concentrations of $\mathrm{O}$ and $\mathrm{H}$ at this height, but not at the adjacent height of $83.256 \mathrm{~km}$. This is extremely unlikely given the rate of vertical mixing through diffusion which would result. Presumably, the suddenly appeared double peaks of the trail should be the result of deformation due to turbulence, which further indicates that the trail formed somewhere else and was then advected into the laser beam by the horizontal wind. The decay rate of the trail is consistent with the removal rate in Fig. $5 c$, but could also result from advection out of the laser beam. 


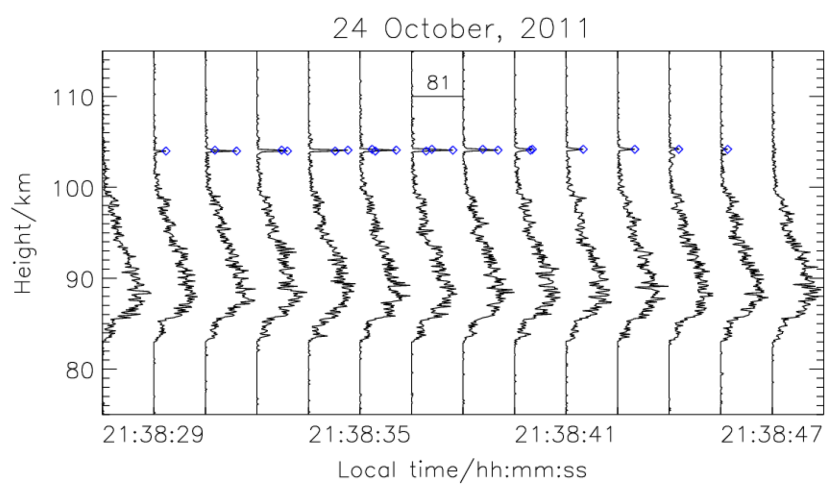

Figure 10. Evolution of a typical meteor trail observed on the top side of the Na layer, which occurred on 24 October 2011.

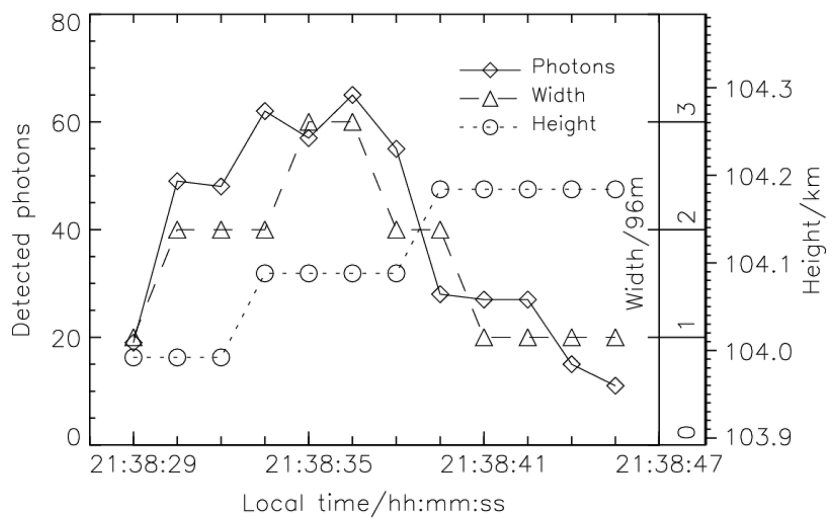

Figure 11. Variations of the trail peak intensity, the width and the peak height, corresponding to Fig. 10.

\section{Case 2: meteor trails on the topside of the sodium layer}

Figure 10 shows an example of meteor trails observed on the topside of the sodium layer, which also appeared on 24 October 2011. It occurred at the altitude of $104.088 \mathrm{~km}$, where the background layer hardly exists, so the evolution of this trail was demonstrated clearly. It was observed in 12 consecutive profiles, i.e. for about $18 \mathrm{~s}$. Initially, the trail appeared in the field of view suddenly; then it grew rapidly and spread upward. Subsequently it decayed little by little, while the emerging upper segment began to grow sharply, and then became the strongest. In the following instants it decayed somewhat and the trail went on broadening upward. Subsequently, it grew slightly and the new higher segment increased by a relatively large extent, reaching a maximum of 4405 atoms $\mathrm{cm}^{-3}$. In the following samples, all segments kept on decaying until the trail disappeared. It appears to be a common feature of our data that at each altitude channel the formation period is shorter than the decay period.

Figure 11 illustrates the variations of the peak intensity, the peak height and the width of this trail event. It was confined

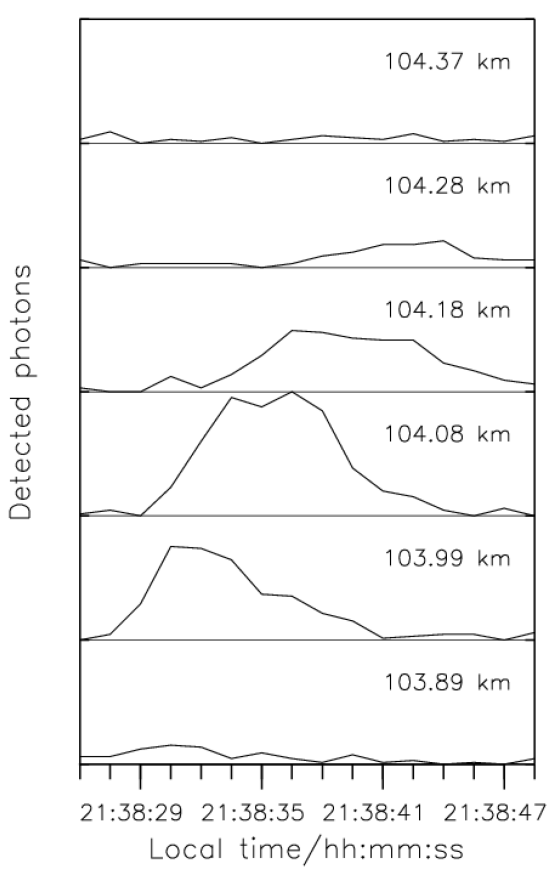

Figure 12. Temporal variation of the lidar returned signals at different altitudes, corresponding to Fig. 10.

to three altitude channels of $96 \mathrm{~m}$. It widened first and then narrowed. It kept on moving upward during the whole process. Figure 12 shows the returned signal variation from different heights. Signals from 104.37 and $103.89 \mathrm{~km}$ did not show any trend at all, indicating they were not affected by the trail event. Signals from the other four heights exhibited an obvious growth and decay process, and for the two strongest their growth time was far shorter than their decay time. The signal at $103.99 \mathrm{~km}$ reached the maximum within $1.5 \mathrm{~s}$ and began to decay gradually, when the signal at $104.08 \mathrm{~km}$, one altitude bin higher, started to grow rapidly. The signal at $104.18 \mathrm{~km}$ exhibited a rather similar variation trend to that at $104.08 \mathrm{~km}$, and later became the strongest. Note the signal from $104.28 \mathrm{~km}$. At the beginning, it did not show any variation. Subsequently, it continued increasing when all the others decreased, although it never reached the preset meteor threshold. Note that there was an obvious phase difference between the growth process and the decay at different altitude channels, which might indicate that the trail was deformed into turbulent structures immediately after the meteoroid ablated.

\section{Case 3: meteor trails near the peak background of the sodium layer}

Figure 13 shows an example of meteor trails occurring near $92 \mathrm{~km}$, which was observed on 27 June 2011. At 00:30:16 LT, a trail appeared at $91.704 \mathrm{~km}$, and began to increase in intensity, and broaden upward. The signal from the next higher channel $(91.800 \mathrm{~km})$ then intensified and became the 


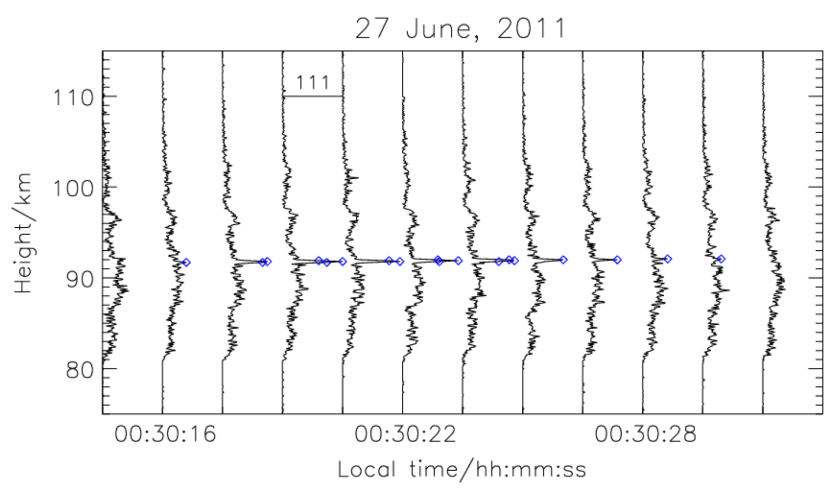

Figure 13. Evolution of a meteor trail observed near the peak background of the Na layer, which occurred on 27 June 2011.

strongest part soon after, corresponding to a maximum of 4280 atoms $\mathrm{cm}^{-3}$. The whole trail began to decrease together until a new upper segment $(91.896 \mathrm{~km})$ started increasing in intensity, becoming the strongest within $3 \mathrm{~s}$. Subsequently this segment also began to decrease rapidly, but the upper part of the trail $(91.992 \mathrm{~km})$ continued increasing for another profile before starting to decrease gradually, at this point becoming the strongest segment. At the new upper height $(92.088 \mathrm{~km})$, the trail intensity increased slowly, becoming the strongest segment at the end of the event.

Figure 14 shows the variations of the peak intensity, the peak height and the width of the trail. The whole event lasted for 10 profiles, $\sim 15 \mathrm{~s}$. The rise time was $\sim 3 \mathrm{~s}$, far shorter than the decay time of $\sim 10.5 \mathrm{~s}$ The event was confined to five altitude channels, and continued moving upward during the whole process. Figure 15 illustrates the temporal variation of signals returned from different heights. Signals from the lowest height $(91.608 \mathrm{~km})$ and the highest heights $(92.184$ and $92.280 \mathrm{~km}$ ) did not show any variation trend, indicating that they were unaffected by the trail event. Signals from other heights exhibited obvious variation trends. Note that the peak intensity from upper heights always appeared later than that from lower heights during this trail event. We investigated all the trails longer than $7.5 \mathrm{~s}$, a total of 97 events. For 45 events, the peak intensity at lower heights lagged behind that at upper heights; for 25 trails, the peak intensity at lower heights led that seen at upper heights; for 10 events, the peak intensity at lower heights was in phase with that seen at upper heights and 17 events were observed in only one altitude channel. Trails with the peak intensity at lower heights lagging behind that at upper heights are significantly more frequent ( $\sim 1.8$ times) than those with the peak intensity at lower heights leading that at upper heights. We also observe that trails for which the peak intensity at lower heights leads that at upper heights appeared to occur at greater heights than those behaving in the opposite manner. The orientation of these long-duration trails is good evidence that they were produced outside the laser beam and then advected into it.

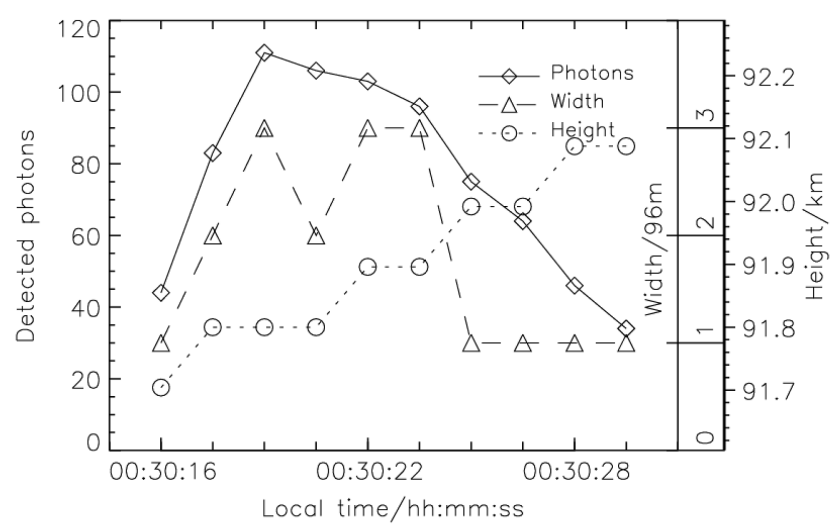

Figure 14. Variations of the trail peak intensity, the width and the peak height, corresponding to Fig. 13.

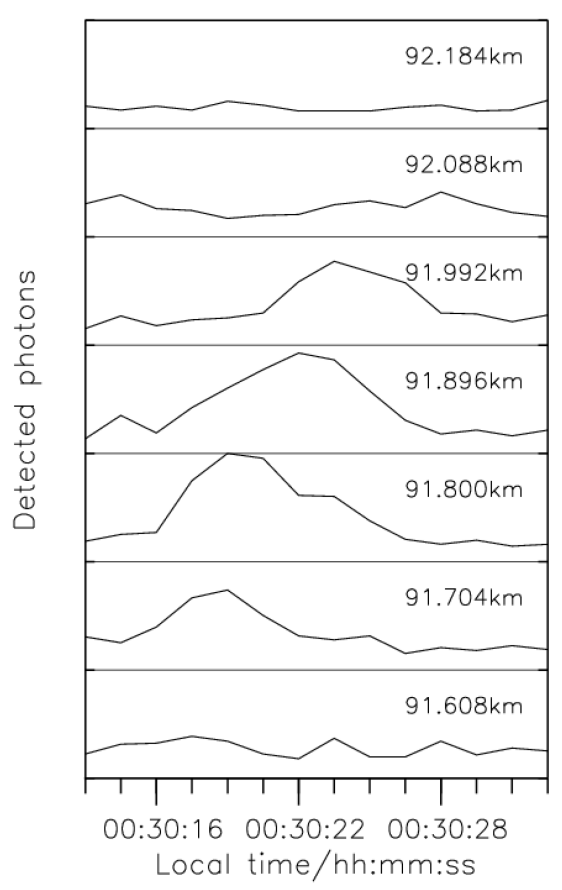

Figure 15. Temporal variation of the lidar returned signals at different altitudes, corresponding to Fig. 13.

In summary, these long-duration ( $>7.5 \mathrm{~s}$ ) trails consist of density enhancement bursts. In the altitude range influenced by the trail, signals from each altitude channel exhibited a growth and decay process, usually with the growth process faster than the decay process. In addition, we saw a consistent phase difference between the density enhancement bursts at different altitudes. Given that these long-duration trails appeared above $79 \mathrm{~km}$ (as shown in Fig. 3) where diffusional removal far exceeds chemical removal (as calculated in Fig. 5b) and the lifetime of $\mathrm{Na}$ trails is less than $10 \mathrm{~s} \mathrm{(as}$ shown in Fig. 5c), these Na trails should fade into the background due to diffusion, but could also be advected out of the laser beam by the horizontal wind. 


\section{Conclusion}

Based on a total of $\sim 680 \mathrm{~h}$ of $1.5 \mathrm{~s}$ sodium lidar observations made at Yanqing, China, we extracted 1382 meteor trails and analysed the characteristics of these trails. This is so far the largest data set that has been used to analyse lidar-observed meteor trails. The occurrence height of these trails was found to follow a bi-modal distribution, with peaks around 83.5 and $95.5 \mathrm{~km}$, respectively. The long-term variation of the occurrence height shows that an increased fraction of meteor trails appeared at higher altitudes in August and September 2010. This seasonal variation may be associated with meteors showers, or a greater contribution of meteors from the Helion source during summer at mid-latitudes (Pifko et al., 2013). The double-peak height distribution probably reflects populations of meteoroids from non-Apex and anti-Apex sources. We found that $4.7 \%$ of the atomic trails (65 events) were detected below $80 \mathrm{~km}$, with three of them lasting more than $15 \mathrm{~s}$, and $3.3 \%$ of them (45 events) were found above $100 \mathrm{~km}$. These small percentages are expected because of rapid chemical removal of metal atoms on the bottom side of the layer and rapid diffusional dilution on the top side (Höffner et al., 1999; Kane and Gardner, 1993; $\mathrm{Xu}$ and Smith, 2003). Kane and Gardner (1993) did not observe trails below $82 \mathrm{~km}$ or above $96 \mathrm{~km}$, but their lidar was less sensitive than the instrument used in our study.

We analysed the duration of the trails in the laser beam and found that it varied from $\sim 1.5$ to $\sim 75 \mathrm{~s} ; 75 \%$ of all trails were observed in only one profile, which indicates that their residence time in the laser beam was not greater than $1.5 \mathrm{~s}$. Considering the laser beam divergence of less than $0.2 \mathrm{mrad}$, this short lifetime may be partly the result of advection of the trails through the laser beam, although the lifetime due to diffusional/chemical removal is also on the order of $1 \mathrm{~s}$ for meteoroids less than $1 \mathrm{mg}$ in mass (Fig. 5). Further experiments with different laser beam divergences should help clarify this question.

The trail peak density exhibited a vertical distribution similar to that of the long-term background Na layer, which suggests that the stronger trails determine the shape of the trail peak density distribution and that the weaker trails tend to be observed away from the background peak height. The raw occurrence height of these trails was weighted by the probability of observation, producing a very clear bi-modal distribution peaks at $\sim 83$ and $\sim 96 \mathrm{~km}$. The higher peak should correspond to a meteoroid population with speeds between 20 and $30 \mathrm{~km} \mathrm{~s}^{-1}$, whereas the lower peak should arise from much slower particles in a near-prograde orbit. It is inferred that the majority of meteoroids that generated these trails have masses of $\sim 1 \mathrm{mg}$.

The evolution of long-duration meteor trails was investigated. It shows that within the altitude range influenced by the trail event, signals from each altitude channel exhibited obvious growth and decay processes, usually with the formation period shorter than the decay time. It is noteworthy that there existed a consistent phase difference among the peak intensities at different heights, which might indicate that trails were deformed into turbulent structures immediately after they ablated. It should be possible to clarify this behaviour via modelling studies.

Acknowledgements. We are grateful to the Chinese Meridional Project for providing the sodium lidar data. We acknowledge financial support from the Fundação de Amparo à Pesquisa do Estado de São Paulo - FAPESP, the National Natural Science Foundation of China through grant 41104101, and project number 291332 from the European Research Council.

Topical Editor C. Jacobi thanks three anonymous referees for their help in evaluating this paper.

\section{References}

Brosch, N., Häggström, I., Pellinen-Wannberg, A., and Westman, A.: Unusual features in high statistics radar meteor studies at EISCAT, Mon. Not. R. Astron. Soc., 401, 1069-1079, 2010.

Campbell-Brown, M. D. and Jones, J.: Annual variation of sporadic radar meteor rates, Mon. Not. R. Astron. Soc., 367, 709-716, 2006.

Ceplecha, Z., Borovička, J., Elford, W., ReVelle, D., Hawkes, R., Porubčan, V., and Šimek, M.: Meteor Phenomena and Bodies, Space Sci. Rev., 84, 327-471, 1998.

Chu, X. Z., Pan, W. L., Papen, G., Gardner, C. S., Swenson, G., and Jenniskens, P.: Characteristics of Fe ablation trails observed during the 1998 Leonid meteor shower, Geophys. Res. Lett., 27, 1807-1810, doi:10.1029/1999GL010756, 2000.

Crank, J.: The Mathematics of Diffusion, Oxford University Press, Oxford, 1975.

Gerding, M., Alpers, M., Höffner, J., and von Zahn, U.: Simultaneous $\mathrm{K}$ and $\mathrm{Ca}$ lidar observations during a meteor shower on March 6-7, 1997, at Kühlungsborn, Germany, J. Geophys. Res.Space, 104, 24689-24698, doi:10.1029/1999JA900338, 1999.

Grime, B., Kane, T., Collins, S., Kelley, M., Kruschwitz, C., Friedman, J., and Tepley, C.: Meteor Trail Advection and Dispersion; Preliminary Lidar Observations, Geophys. Res. Lett., 26, 675678, doi:10.1029/1999GL900053, 1999.

Helmer, M. and Plane, J. M. C.: A study of the reaction $\mathrm{NaO}_{2}+\mathrm{O} \rightarrow \mathrm{NaO}+\mathrm{O}_{2}$ : Implications for the chemistry of sodium in the upper atmosphere, J. Geophys. Res.-Atmos., 98, 23207-23222, 1993.

Höffner, J., von Zahn, U., McNeil, W. J., and Murad, E.: The 1996 Leonid shower as studied with a potassium lidar: Observations and inferred meteoroid sizes, J. Geophys. Res.-Space, 104, 2633-2643, doi:10.1029/1998JA900063, 1999.

Janches, D., Heinselman, C. J., Chau, J. L., Chandran, A., and Woodman, R.: Modeling the global micrometeor input function in the upper atmosphere observed by high power and large aperture radars, J. Geophys. Res.-Space, 111, A07317, doi:10.1029/2006JA011628, 2006.

Kane, T. J. and Gardner, C. S.: Lidar Observations of the Meteoric Deposition of Mesospheric Metals, Science, 259, 1297-1300, 1993. 
Liu, J. B. and Yi, F.: Sodium resonance lidar observations during 2001 Leonid meteor shower over Wuhan, Chinese Sci. Bull., 49, 303-306, 2004.

Liu, Y. J., Clemesha, B. R., Wang, J. H., and Cheng, X. W.: Comparison of sporadic sodium layer characteristics observed at different time resolutions, Ann. Geophys., 31, 1899-1912, doi:10.5194/angeo-31-1899-2013, 2013.

Love, S. G. and Brownlee, D. E.: A direct measurement of the terrestrial mass accretion rate of cosmic dust, Science, 262, 550553, 1993.

Marsh, D. R., Janches, D., Feng, W., and Plane, J. M. C.: A global model of meteoric sodium, J. Geophys. Res.-Atmos., 118, 11442-11452, doi:10.1002/jgrd.50870, 2013.

Pifko, S., Janches, D., Close, S., Sparks, J., Nakamura, T., and Nesvorny, D.: The Meteoroid Input Function and predictions of mid-latitude meteor observations by the MU radar, Icarus, 223, 444-459, 2013.

Plane, J. M. C.: Atmospheric chemistry of meteoric metals, Chem. Rev., 103, 4963-4984, 2003.

Plane, J. M. C.: A time-resolved model of the mesospheric Na layer: constraints on the meteor input function, Atmos. Chem. Phys., 4, 627-638, doi:10.5194/acp-4-627-2004, 2004.

Plane, J. M. C.: Cosmic dust in the earth's atmosphere, Chem. Soc. Rev., 41, 6507-6518, 2012.
Rapp, M., Strelnikova, I., and Gumbel, J.: Meteoric smoke particles: Evidence from rocket and radar techniques, Adv. Space Res., 40, 809-817, 2007.

Sugar, G., Oppenheim, M. M., Bass, E., and Chau, J. L.: Nonspecular meteor trail altitude distributions and durations observed by a $50 \mathrm{MHz}$ high-power radar, J. Geophys. Res.-Space, 115, A12334, doi:10.1029/2010JA015705, 2010.

Vondrak, T., Plane, J. M. C., Broadley, S., and Janches, D.: A chemical model of meteoric ablation, Atmos. Chem. Phys., 8, 70157031, doi:10.5194/acp-8-7015-2008, 2008.

von Zahn, U., Gerding, M., Hoffner, J., McNeil, W. J., and Murad, E.: Iron, calcium, and potassium atom densities in the trails of Leonids and other meteors: Strong evidence for differential ablation, Meteorit. Planet. Sci., 34, 1017-1027, 1999.

Wang, W., Killeen, T. L., Burns, A. G., and Roble, R. G.: A highresolution, three-dimensional, time dependent, nested grid model of the coupled thermosphere-ionosphere, J. Atmos. Sol.-Terr. Phy., 61, 385-397, 1999.

$\mathrm{Xu}$, J. and Smith, A. K.: Perturbations of the sodium layer: controlled by chemistry or dynamics?, Geophys. Res. Lett., 30, 1-9, doi:10.1029/2003GL018040, 2003.

Zeng, L. and Yi, F.: Lidar observations of $\mathrm{Fe}$ and Na meteor trails with high temporal resolution, J. Atmos. Sol.-Terr. Phy., 73, 2367-2372, doi:10.1016/j.jastp.2011.08.002, 2011. 